\title{
TTR
}

Traduction, terminologie, re?daction

\section{Présentation regroupée des traductions du poème}

Volume 12, numéro 2, 2e semestre 1999

Poésie, cognition, traduction II - Autour d'un poème de W. H. Auden

Poetry, Cognition, Translation II — On a Poem by W. H. Auden

URI : https://id.erudit.org/iderudit/037375ar

DOI : https://doi.org/10.7202/037375ar

Aller au sommaire du numéro

\section{Éditeur(s)}

Association canadienne de traductologie

\section{ISSN}

0835-8443 (imprimé)

1708-2188 (numérique)

Découvrir la revue

Citer ce document

(1999). Présentation regroupée des traductions du poème. TTR, 12(2), 117-129. https://doi.org/10.7202/037375ar d'utilisation que vous pouvez consulter en ligne.

https://apropos.erudit.org/fr/usagers/politique-dutilisation/ 


\section{Présentation regroupée des traductions du poème}

« Où vas-tu donc ? dit le lecteur au cavalier, La vallée est mortelle quand les fourneaux brûlent, Le fumier s'y entasse et ses odeurs affolent, Ce trou est une tombe où reviennent les forts. »

« Et crois-tu donc, dit le craintif au voyageur, Que tu vas atteindre le col avant la brune, Que ton cil diligent va découvrir le vide Reconnu par tes pieds entre l'herbe et la pierre?"

"Quel était cet oiseau? dit l'horreur à l'oreille, As-tu vu cette forme entre les arbres tors?

Cette ombre te poursuit, silencieuse et rapide, La tache sur ta peau est un mal scandaleux. "

"Va-t-en d'ici », dit le cavalier au lecteur, " Les tiens, jamais », dit le voyageur au craintif, "Ils ne cherchent que toi », dit l'oreille à l'horreur, Comme il les laissait là, comme il les laissait là.

Tr. Jean LAMBERT, W. H. Auden Poésies choisies, (Paris, Gallimard, 1977) 
« Où vas-tu donc? ", dit au licteur le lecteur "Le val est fatal où des fagots flambent, Du fumier du tas mol les odeurs affolent, La combe est une tombe qui nul ne console. "

" Penses-tu donc », dit le couard au coureur, "Que la nuit ne colle pas au sol du col. Qu'à bien chercher, tu chasses ce qui se cache, Que tes pas du granit au gazon relâchent? »

« Drôle d'oiseau! », dit l'horreur à l'auditeur, " As-tu vu la chose dans l'arbre baroque?

Taisant se tapit à côté le fantôme,

La vraie vérole te vaut un hématome. »

« Sors de ces lieux! », dit au lecteur le licteur "C'est toi l'échec! », dit au couard le coureur, "C'est toi qu'on suit », dit l'horreur à l'auditeur Qui laissa les autres là, qui les laissa.

Tr. Didier COSTE (inédit, 1990) 
"Oh para onde é que vais? » diz quem conta a quem [monta,

esse vale é fatal de arder tanta fornalha, além fica a estrumeira cujo cheiro estropia, quem se ergue alto regressa à cova nessa falha

" Oh então imaginas », diz quem teme a quem dista que haverá lusco-fusco em teu curso atrasado, tua vista sem falta descobrindo o que falta aos teus passos gravar do granito ao relvado?

« Oh mas que ave era aquela », diz o horror ao ouvinte, « viste em árvores tortas dessa forma a presença? atrás de ti ligeira eis se esgueira a figura, a mancha em tua pele repele e é de doença

" Já fora desta casa » - diz quem monta a quem conta, "Nunca a tua o fará " - diz quem dista a quem teme, "Vêm em busca de ti » - diz o ouvinte ao horror, quando lá os estreme, quando lá os estreme.

Tr. Vasco GRAÇA MOURA (inédit, 1995) 


\section{Épilogue}

" Mais où vas-tu donc?, dit le lecteur au marcheur, Quand fument ses fourneaux cette vallée est traître, Il y traîne un fumier dont les odeurs affolent, Ce trou est une tombe où retournent les maîtres. »

" Mais qu'espères-tu, dit le trembleur au flâneur, L'ombre va retarder ton cours vers le passage Et ton cil diligent saura-t-il voir le vide Que tes pas sentiront entre pierre et herbage?»

" Mais quel est cet oiseau? », dit l'horreur au veilleur, « As-tu vu cette chose entre les nœuds des arbres? Derrière toi, rapide, une forme se glisse, La tache sur ta peau est un mal exécrable. »

" Hors de cette étude », - dit le marcheur au lecteur, " Tu n'y verras rien ", — dit le flâneur à l'horreur, "On te court après ", - dit le veilleur à l'horreur, Alors qu'il les quittait, alors qu'il les quittait.

Tr. Charlotte MELANÇON 


\section{Les trois compagnons}

« Mais où t'en vas-tu? dit le lecteur au marcheur, Ce vallon est fatal où fument les fourneaux, Un fumier y répand des relents répugnants, Cette fosse est de tous les vivants le tombeau. »

« T'imagines-tu, dit le méfiant à l'errant, Que tu auras franchi le col avant la nuit, Et que ton œil perçant apercevra à temps Les périls du sentier du roc jusqu'aux prairies? »

« Ne vois-tu cet oiseau, dit l'horreur au guetteur, Ne l'as-tu aperçu dans les arbres noueux? À pas furtifs et lents il s'approche de toi Oh! ces grains sur ta peau révèlent un mal affreux! »

" Hors de ta maison ", dit le marcheur au lecteur, "Le péril est le tien », dit l'errant au méfiant, "C'est toi qu'on poursuit », dit le guetteur à l'horreur, Avant de les quitter, avant de les quitter.

Tr. Patricia GODBOUT 


\section{Les trois compagnons}

Où vas-tu donc ainsi? dit Liseur à Marcheur Fatale est la vallée quand flambent les fabriques, Là-bas est le fumier à l'odeur infâmante Cette faille est la fosse où retournent les grands.

T'imagines-tu donc, dit Peureux à Curieux Que le soir attendra que tu sois à la passe Que ton ceil diligent discernera le vide Que ton pas glissera du granit au gazon?

Qu'était donc cet oiseau? dit l'Horreur à l'Oreille As-tu vu cette forme en ces arbres tordus? Derrière toi sournoise s'est glissée une ombre. Ces taches sur ta peau sont une peste atroce.

Hors de cette maison, dit Marcheur à Liseur Jamais tu ne pourras, dit Curieux à Peureux. C'est toi qu'ils traquent ici, dit l'Oreille à l'Horreur, Et il les laissa là, et il les laissa là.

Tr. Christine KLEIN-LATAUD 


\section{Les trois compagnons}

" Oh! où allez-vous? » dit le lecteur au crypteur, "La vallée est fatale quand brûlent les fourneaux, Là-bas le purin, ces odeurs putrides Ce trou est une tombe où revient le bel homme. "

« Oh! imaginez », dit le craintif au coursier, "Que l'aube retarde le passage de la passe, Votre regard diligent découvre le manque Que vos pas ressentent du granit au gazon? »

"Oh! qu'est-ce que cet oiseau? » dit l'horreur au coureur « As-tu vu cette forme aux arbres tortillés $\mathrm{Au}$ fond surgit une figure silencieuse La peau tachée n'est que signe d'un mal. »

"Fuis la maison ", - dit le crypteur au lecteur, " Jamais la tienne ", - dit le coursier au craintif, "On te guette ", - dit le coureur à l'horreur, Et ainsi il les abandonne, les abandonne.

Tr. Serge GAVRONSKY 


\title{
Les trois compagnons
}

\author{
Où aller? \\ Fatal fourneau \\ Odeurs \\ la tombe \\ Imagine \\ le délai \\ regarde \\ l'herbe
}

Cet oiseau

L'arbre

figure doucement

la peau

Cette maison dit le jamais

ils

là.

Tr. Serge GAVRONSKY 


\section{Les trois compères}

«Où vas-tu donc ainsi? demanda le lecteur Dans la vallée des fours donnent la mort Donnent la mort De la fosse montent là-bas de folles odeurs De folles odeurs

Le creux de la combe du preux est la tombe Du preux est la tombe. »

«Oh! ne crois-tu pas, demanda la peur, Qu'en allant au pertuis la trompeuse nuit La trompeuse nuit À ton cil vigilant cachera le vide Cachera le vide Et de la pierre au pré seras précipité? Seras précipité. »

"Quel était cet oiseau? demanda l'horreur Et cette forme apparue dans les arbres tordus?

Dans les arbres tordus

L'ombre furtive te suit en silence

Te suit en silence

La tache sur ta peau est une pestilence Est une pestilence. »

" Loin du foyer » - répondit le chevalier " Jamais au tien " - répondit le pèlerin " Est venue ton heure » - répondit le lecteur Et les autres quitta, les autres quitta.

Tr. Annie BRISSET 


\section{Les Trois Miséreux}

" Où vas-tu, Veilleur? crie le Veule, La lande, là-bas, est pestilente la lune y luit comme la prunelle opaque d'une âme malévolente. »

"Pourquoi, Actif, s'écrie l'Assis, t'éloignes-tu de ton foyer? Déjà, autour des grands fossés les loups commencent à tournoyer. »

« Sais-tu, Mage, dit le Morfondeur que l'œil béant de Dieu te guette pour punir, dans les profondeurs, ta soif de science et d'enquête? »

« Loin de toi, Veule! » répond Veilleur, " Pour vivre, Assis! » réplique Actif, «Au diable! crie Mage au Morfondeur, Je n'ai que faire de vous, chétifs $» . .$.

Tr. Barbara FOLKART 


\section{Les Trois Miséreux}

« Où vas-tu, Voyageur? s'écrie le Veule, Là-bas, à l'est, la lande est pestilente, la nuit t'y nuira : comme un grand linceul elle s'abattra sur toi, silente et lente. »

« Pourquoi pars-tu, Passeur? demande la Peur, N'entends-tu pas ces cris dans la forêt?

Dans chaque clairière un bûcher se prépare: les flammes réclament tes os à dévorer. »

«Méfie-toi, Randonneur! dit Repentir Ce territoire est traitre, plein de trous, spongieux, labile, habile à engloutir les glorieux - sans trace, et d'un seul trait. »

« Loin de tes veuleries! » crie Voyageur, " Pour effacer ta face! » répond Passeur, "Mes pieds sont clairvoyants! » rit Randonneur, ivre déjà du vin de l'avenir.

Tr. Barbara FOLKART 


\section{Les Trois Miséreux}

« Pourquoi sors-tu? dit Lecteur à l'acteur Le vent des fournaises, haleine mortifère, répand la folie; l'odeur des ordures dérangent les géants qui gisent sous la terre. »

«Tu ne vas pas seul, dit Peur au passeur, grimper jusqu'au col entre chien et loup? Tes pieds, sans lumière, n'y verront pas clair : la voix arrachée, tu cherras en-sous. »

«Qu'est-ce qui bruit? crie Horreur à l'oreille, Les cyprès frémissent dans la brune tardive, voilà qu'elle arrive, cette ombre furtive, pour strier ta peau de stigmates vermeils. »

« Lire est un leurre! » crie l'acteur à Lecteur, « Mes pieds sont sûrs! » crie le passeur à Peur, « Meurs de terreur! » crie l'oreille à Horreur, en laissant ces gueux, en laissant ces gueux

\section{Tr. Barbara FOLKART}




\section{Les Trois Miséreux}

« Où t'en vas-tu? dit Lecteur à l'acteur, La mort sort des fours, vidant la vallée, l'odeur des ordures répand la folie, les grands, par cet antre, rentrent sous terre. "

« Tu n'imagines pas, dit Peur au passeur, atteindre le Pas avant la nuit noire?

Tes pieds démunis, n'y pouvant voir goutte, lâcheront le granite, amorceront ta chute. »

"Que crie la corneille? dit Râle à l'oreille, Une ombre louche chuchote à ton épaule, dans cet arbre torve un corps se tortille, sur ta peau éclôt la fine fleur du mal. »

« Loin du logis! » crie l'acteur à Lecteur, " Mes pieds pourront! » crie le passeur à Peur, " Oiseau de misère! » crie l'oreille à Râle, en s'éloignant seule, en s'éloignant seule

Tr. Barbara FOLKART 